\title{
Thrombolysis in Myocardial Infarction Flow-1
}

National Cancer Institute

\section{Source}

National Cancer Institute. Thrombolysis in Myocardial Infarction Flow-1. NCI Thesaurus.

Code C100041.

Penetration without perfusion: The contrast material passes beyond the area of obstruction, but fails to opacify the entire coronary bed distal to the obstruction for the duration of the cine run. (www.TIMI.org accessed 21SEP2011) (ACC) 